\title{
Low- level laser: cost of therapy fornipple trauma
}

Danielly Negrão Guassú Nogueira 1

iD https://orcid.org/0000-0003-3070-4378

Franciane Maria da Silva Curan 2

iD https://orcid.org/0000-0002-9786-5451

Alexandrina Aparecida Maciel Cardelli 3

(iD http://orcid.org/0000-0002-0222-8821

Rosângela Aparecida Pimenta Ferrari 4

iD http://orcid.org/0000-0003-0157-7461

\author{
Tatiane Tokushima 5 \\ iD http://orcid.org/0000-0002-8139-339X \\ Rodrigo Antônio Carvalho Andraus 6 \\ (iD) http://orcid.org/0000-0002-3849-0872
}

1-5 Programa de Pós-graduação em Enfermagem. Universidade Estadual de Londrina. Av. Robert Koch, 60. Vila Operária. Londrina, PR, Brasil. CEP: 86.057-970. E-mail: dani.saude@yahoo.com.br

6 Programa de Pós-graduação em Ciências da Reabilitação. Universidade do Norte do Paraná. Londrina, PR Brasil.

\begin{abstract}
Objectives: to measure the micro-cost of local laser therapy (LL) and transcutaneous laser therapy application by Irradiation Laser Intravascular of Blood (ILIB) to treat nipple trauma and compare the most effective and efficient alternative treatment.

Methods: a cross-sectional analytical and quantitative study with analysis on the micro absorption cost, implemented as a clipping, from a randomized clinical trial that used two types of laser therapy to treat nipple trauma due to breastfeeding. The sample consisted of 101 nipple lesions. Patients were randomized into three groups (Control - CG, Local Laser $L L G$ and ILIB-ILIBG). Materials used, direct labor (DL) and laser equipment were predictors of costs. The delta calculation (effect size) was the indicator for measuring effectiveness and efficiency.

Results: after three sessions, the average final cost was $R \$ 40.04$ for $C G, R \$ 53.55$ for $L L G$ and $R \$ 67.29$ for ILIBG. After three sessions of treatment, ILIBG showed a great reduction in the lesion area, but with a higher cost $(p<0.05)$.

Conclusions: ILIBG had a better effect on healing the nipple trauma when compared to $C G$ and $L L G$, even though it is more expensive, it suggests a positive cost-benefit and the most effective and efficient alternative treatment.
\end{abstract}

Key words Low-level laser therapy, Maternal breastfeeding, Costs and cost analysis

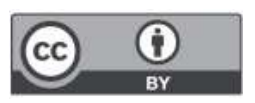




\section{Introduction}

Globally, maternal breastfeeding is one of the most widespread topics due to its impact on child's protection and nutrition, however, the low prevalence of breastfeeding is a major public health problem in Brazil and worldwide. It is estimated that the increase of breastfeeding through efficient and vigorously implemented public policies could prevent around 820 thousand annual deaths of children under the age of five and 20 thousand annual deaths of women due to breast cancer. ${ }^{1}$

Some circumstances can become impairments or complications for maternal breastfeeding, as Nipple Trauma (NT), one of the main causes of early weaning, due to the pain and discomfort it causes. ${ }^{2}$ Studies show that these complications can occur up to the fifteenth day postpartum, with $40 \%$ of the patients already presenting lesions, breast engorgement and breast pain in the first 24 hours of postpartum. ${ }^{3}$

The Low-Level Laser (LLL) has become a powerful ally for offering anti-inflammatory, healing effects, besides reducing the pain caused by lesions, ${ }^{4}$ and other studies ${ }^{5-7}$ have already shown its effectiveness in healing NT and pain during breastfeeding.

Thus, LLL therapy can be performed using two distinct modalities, applying the laser directly to the lesion site, called Local Laser (LL) Therapy, or applying the transcutaneous laser, called Irradiation Laser Intravascular of Blood (ILIB). This is performed through a bracelet attached to the patient's wrist over the radial artery to irradiate the blood systemically. 8

Treatment with LLL is accordingly regulated by the Conselho Federal de Enfermagem do Brasil (Federal Nursing Council of Brazil) under COFEN opinion number. $13 / 2018^{9}$ where it is clear for the necessity of specific training so that nurses can use laser therapy in the implementation of nursing care.

Furthermore, in the Politica Nacional de Práticas Integrativas e Complementares (PNPIC) (National Policy of Integrative and Complementary Practices) 10 laser therapy is an alternative treatment, however it is not yet included in the list of procedures paid for by the Sistema Único de Saúde (SUS) (Brazilian Public Health System), requiring economic analysis and effectiveness studies, for possible inclusion for this purpose.

It is worth noting that, to date, there are unknown costs on these two alternatives treatment for NT, both in Brazil and internationally, making this the first study to use ILIB for NT treatment, as well as to analyze the efficiency of LLL concerning micro-costing from the perspective of the health services manager.

In this respect, cost management is a managerial tool to support decision making, which can often be influenced by the cost and effectiveness of a given procedure, especially when it comes to the incorporation of new technology in public health services, which are in search of low cost and high impact interventions in care practice. 11

We expect that this study can guide health professionals in choosing the best therapeutic modality, including cost information in the decisionmaking process, since investments in the acquisition of new equipment, specific training for health professional and the labor time spent in laser therapy.

Given the above, this study aimed to measure the micro-cost of the Local Laser (LL) therapy and transcutaneous therapy using Irradiation Laser Intravascular of Blood (ILIB) in the treatment of nipple trauma and to compare the most effective and efficient alternative treatment.

\section{Methods}

A cross-sectional, analytical, quantitative study with micro-cost analysis of the absorption cost, implemented as a clipping of a randomized clinical trial carried out at the Human Milk Bank (HMB) at a university hospital in the South of Brazil, exclusively assisted by SUS. The hospital already has other research projects using LLL in other specialties and has shown interest in establishing laser therapy as another alternative for treating nipple trauma, which is the reason for choosing this location.

As for ethical aspects, this study was approved by the Research Ethics Committee of the University (Opinion number 2,488,363 / CAAE 71847817.3.0000.5231). All patients signed an informed consent form.

Women over 18 years of age who had a breast injury and who reported pain when breastfeeding were included in the study. The sample was by convenience, the selection was from December 2017 to June 2018 , so that all women who were assisted at the HMB with breast lesions were invited to participate in the study. Exclusion criteria were malignant previous history or pathologies of the breasts, use of medication, mastitis, cognitive impairment, photosensitivity and breast implants. Among mothers who sought HMB, 65 met the inclusion criteria, however the study ceased with 54 women, totaling 101 nipple lesions, 47 women had lesions on both nipples and 7 
women had lesions on only one nipple. Thus, patients were randomized into three groups: 31 lesions made up the Control Group (CG), 39 lesions the Local Laser Group (LLG) and 31 lesions the Irradiation Laser Intravascular of Blood Group (ILIBG). The unit of analysis was nipple lesions caused by breastfeeding. It is worth mentioning that the study considered the number of nipples injured and not the number of mothers.

As for operational procedures, interventions with laser therapy were called sessions, the first being the inclusion of the patient in the study (1 1 st session); 24 hours after the first intervention (2nd session) and 48 hours after the first intervention (3rd session).

The CG patients received all information concerning the proper management of breastfeeding, consisting of guidance on the correct and comfortable positioning of the mother; areola massage and milking to trigger the ejection reflex; baby positioned close to the mother's body, aligning the head, trunk, and buttocks; during the grip, the baby should grab the entire nipple and part of the areola, so that the nose is free, and the chin touches the breast. 12

The LLG patients, besides all guidelines involving clinical management, received local, punctual, in contact laser irradiation at a dose of $1 \mathrm{~J}$ in the center of the lesion and 8 points with a dose of $3 \mathrm{~J}$ each, totaling $24 \mathrm{~J}$, around areola and breast.

ILIBG patients, besides the information and guidelines regarding clinical management, received ILIB. This took place when coupling the equipment to a bracelet on the patient's non-dominant wrist, emitting laser radiation, with an energy dose of $1 \mathrm{~J} / 100 \mathrm{~mW}$ of power, for 30 consecutive minutes, transcutaneously over the radial artery.

The equipment used was the Laser EC - DMC Therapy, with HeNe semiconductor, $660 \mathrm{~nm}, 100 \mathrm{~mW}$ of power, with a specific protocol for ILIB modality, under Anvisa registration number: 80030810156.

The length and width of the lesion were assessed using a ruler, graduated in millimeters.

The allocation, guidelines for clinical management, laser therapy and measurement of injuries were performed by two qualified nurses 9 and researchers in this study.

Considering the different characteristics of the lesions, the Delta calculation was performed, 13 to identify possible changes after the laser application, following the procedures: $\Delta 1=$ area of the lesion after the 1st application - initial lesion area; $\Delta 2=$ area of the lesion after the 2nd application - area of the lesion after the 1 st application; $\Delta 3=$ area of the lesion after the 3rd application - area of the lesion after the 2 nd application. The Delta calculation eva- luated the size of the effect and was the indicator of effectiveness and efficiency used.

As for cost procedures, we opted for the micro absorption cost system, as a method of calculating costs for goods or services, based on all those related to production, according to classification in direct and indirect costs, fixed and variable. ${ }^{14}$

To identify the direct costs, the Average Direct Cost (ADC) of the procedure was used and for that there was the need to describe the quantity and unit price of each of the materials used in the laser therapy sessions. For indirect costs, the amount paid for the laser equipment was raised; estimated depreciation and maintenance costs of the equipment to calculate an apportionment unit.

The variables material consumption, measurement of the time spent in each session, Direct Labor (DL), laser equipment, depreciation of the equipment, were predictors for calculating the micro absorption cost

The costs of the partial CDM of the materials were added to the apportioned installments of the laser equipment and DL costs, to compose the final cost of the procedure under study.

To define the material resources, at the end of each session, the use of disposable aprons, procedure gloves, masks and a surgical cap was documented. The Material Resources Management division of the hospital under study was asked to describe the material and the amounts paid.

The laser equipment was acquired with resources to encourage research financed by the Araucária Foundation, at R\$ 4,829.00 (US\$ 1,255.55). To calculate the equipment depreciation, the total amount paid was considered, for a period of use of 60 months, divided by 30 days, finding the daily cost of R\$2.68 (\$ 0.69). The redistribution of the apportionment costs in the composition of the final cost was a portion of $\mathrm{R} \$ 0.30$ (\$0.077) per session of laser therapy.

To calculate the Direct Labor (DL) 15 the wages of the last 12 months of the nurse assisting at HMB were considered, the amount per hour of the nurse's work with a workload of 40 hours per week was calculated, obtaining R\$26.62 (\$6.92) per hour. The time spent on the assistance, including guidance, was timed. At the beginning of each session, the nurse started a stopwatch.

All data cost were calculated in the Brazilian currency (R\$) and then exchanged to US currency (\$) for a better comparison of values. The price was: one real $(\mathrm{R} \$)$ is worth 0.26 cents and each dollar is worth 3.88 reais at a currency of May 24th, 2019.

The data were processed and analyzed using the 
SPSS version 20.0 statistical program and are presented in median (minimum-maximum). Initially, the homogeneity of the data was assessed using the Levene test. As the data did not show homogeneity and normality, non-parametric tests were applied. For the cost comparison analysis, comparison of the deltas of the lesion area and duration of sessions between groups, the Kruskal-Wallis test was applied followed by Dunn's post-hoc test. For correlation analyzes, the Spearman test was applied. Given the homogeneity for the time of each session between the groups, the Anova One-way test was applied followed by Tukey's post-hoc test. The effect size for the lesion area deltas was also calculated. The significance level was set at $p<0.05$.

\section{Results}

The final cost of each session and the cumulative final cost (total of three sessions) are shown in Figure 1. For sessions 1, 2 and 3 and in the accumulated sessions, the cost was higher for the intervention with LLG and ILIBG ( $p<0.05$ for all comparisons) compared to CG. Additionally, for the same sessions, the application in ILIBG had a higher cost when compared to the application of LLG $(p<0.01$ for all comparisons). In the second session, there was no difference in the cost between the application of LLG and CG, however, ILIBG had a higher cost compared to CG $(p<0.01)$ and LLG $(p<0.01)$. In this perspective, it was observed that each CG session cost an average of R\$14.20 reais (US\$ 3.69), while the LLG session had an average cost of R\$17.88 reais (US\$ 4.64) and ILIBG at an average cost of R\$ 25.00 reais (US\$ 6.50).

Additionally, we could observe that when performing three sessions, the average cost was R $\$$ 40.04 (US\$ 10.41) for the CG, R $\$ 53.55$ (US\$ 13.92) for the LLG and R\$ 67.29 (US\$ 17.49) for ILIBG, with a significant difference in cost for both interventions (LLG and ILIBG), compared to the CG session ( $p<0.05$ for both) and a higher cost for ILIBG when compared to LLG $(p<0.05)$.

Besides assessing the final mean cost, the cost composition was analyzed. The item that had the highest in cost was the DL of the qualified professional to perform the procedure, varying from 76$94 \%$ of the total cost, as shown in Figure 2. On the other hand, the contribution of the cost of the laser equipment, LLG itself varied from 11-16\%. Concerning ILIBG, the cost of laser equipment was from $9-11 \%$.

Figure 3 shows the correlation data between time and cost of the session. To confirm the healing of the

\section{Figure 1}

Median and final cost range for sessions 1, 2 and 3 and accumulated sessions. Londrina, PR, Brazil, 2017 and 2018

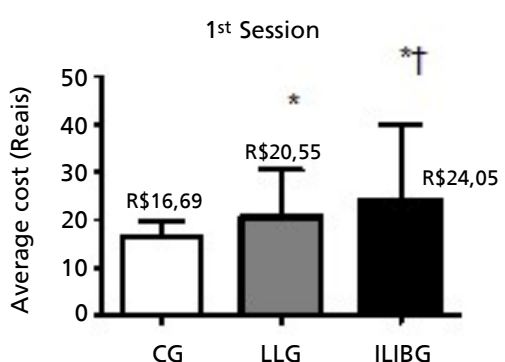

3rd Session

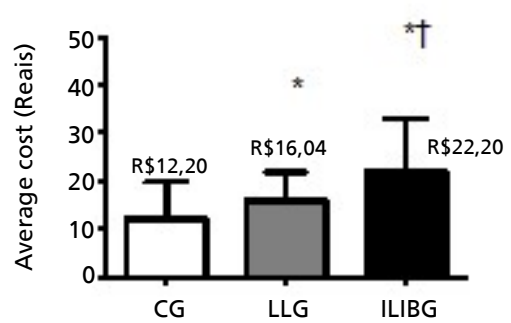

2nd Session

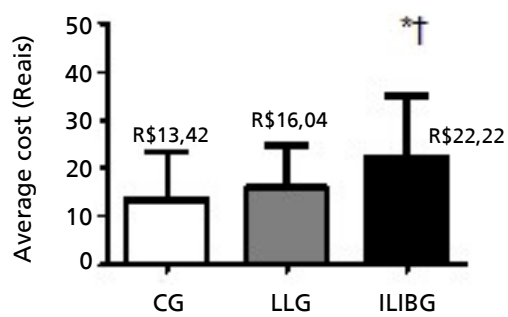

Total of 3 Sessions

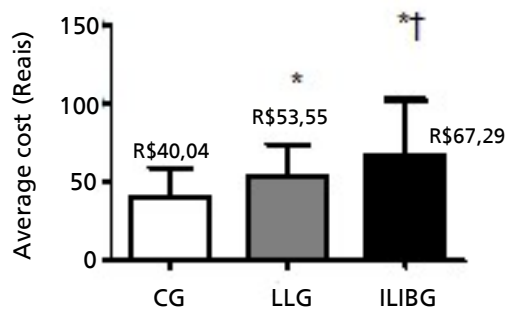

${ }^{\star} p<0.05$ vs. CG; $\dagger p<0,05$ vs. LLG.

CG= Control Group; LLG= Local Laser Group; ILIBG= Irradiation Laser Intravascular of Blood Group. 
lesion, the total session time was correlated with the final Delta $(\Delta)$ value. Thus, it was observed that for all sessions, a strong positive $(r=0.95 ; r=0.96$ and $\mathrm{r}=0.96$, respectively) and significant $(p<0.0001$ for all sessions) session was observed. Moreover, the session duration for ILIBG for the three sessions ( $\mathrm{S} 1=3111 \pm 844$ seconds; $\mathrm{S} 2=2770 \pm 666$ seconds; $\mathrm{S} 3=2679 \pm 638$ seconds) was significantly longer when compared to LLG (S1=2292 \pm 585 seconds; $\mathrm{S} 2=1749 \pm 533$ seconds; $\mathrm{S} 3=1631 \pm 483$ seconds; $p<0.001$ (for all comparisons) and CG ( $\mathrm{S} 1=2052 \pm 288$ seconds; S2 $=1754 \pm 569$ seconds; $\mathrm{S} 3=1540 \pm 576$ seconds; $p<0.001$ for all comparisons.) There was no difference regarding the duration of sessions between CG and LLG ( $p>0.20$ for all comparisons)

The correlation between the total time of the sessions (total time of the three sessions) with the final $\Delta$ (area of the lesion after the 3rd application initial area of the lesion) was performed. In this perspective, a weak negative $(\mathrm{r}=-0.21)$ and significant $(p=0.03)$ correlation were observed between the time of the sessions and the improvement in the lesion. That is, the longer the session, the smaller the final area of the injury.

For the total time, a significant difference was found between the groups $(p<0.001)$. As previously demonstrated, CG and LLG showed a cumulative duration of the three sessions significantly shorter when compared to ILIBG $(p<0.001$ for both). However, when analyzing the improvement of the lesion, only ILIBG showed a greater reduction when compared to the CG $(p=0.01)$.

Table 1 shows the costs of the final Delta (after the $3^{\text {rd }}$ session - initial moment) and the sum of the duration of the three sessions. As for the improvement in the lesion, it was observed that after three sessions, there was a difference only between CG and ILIBG $(p<0.01)$, with no statistically significant differences between CG and LLG and between ILIBG and LLG.

Based on the conditions proposed in this study, to care for the 101 lesions during the data collection months, the direct costs were R $\$ 1,230.65$ (US\$ 319.97) for CG, R\$2,083.73 (US\$ 541.77) for LLG and R\$2,307.61 (US\$ 599.98) for ILIBG, totaling $\mathrm{R} \$ 5,622.00$ (US\$ 1,461.72).

\section{Discussion}

The average costs of sessions that used laser therapy to treat NT (LLG and ILIBG) were higher when compared to $\mathrm{CG}$, which received only clinical management recommendations. Considering that these guidelines were the same in all groups, the difference in time spent was on laser irradiation, since LLG, the laser was irradiated directly on the breast lesion and ILIBG, the laser was irradiated transcutaneously over the radial artery.

When comparing costs between CG sessions, the first session had a higher cost than the third. This decrease may come from educational actions, associated with technical, scientific and practical knowledge, well established in the first session, making the professional take less time in other meetings.

ILIBG had a significantly higher cost when compared to LLG, which can also be explained by the duration of therapy. However, when considering the reality at $\mathrm{HMB}$ and aiming to optimize time, the professional can embrace the mother, install the equipment on the wrist, start irradiation, while performing the breasts' management.

It was evident that in the three groups, the DL of the qualified professional had greater prominence in the final cost of the procedure. Currently, the financial investment for qualification is a choice of the health professional as a feature in his/her career, however, it is believed that making partnerships with universities that have this research line, may be a possibility of expanding the qualification of professionals in laser therapy, to promote breastfeeding in SUS.

This study also showed that the longer the procedure, the higher the cost of each session. Nevertheless, it should be observed that the duration should not be a single criterion for choosing which therapeutic alternative, because it does not allow assessing the clinical efficacy to improve the lesion. However, in the health services management practice, it should be included in the decision making regarding the best choice of treatment modality.

In this perspective, a systematic review compared alternative treatments commonly used for NT healing and analgesia, including medications, ointments, dressings, protective shells, use of breast milk itself, correction of the latch and positioning of the baby, however there is no strong evidence about the effectiveness, besides that these treatments are time-consuming and the woman when seeking help, already has a severe lesion. ${ }^{16}$

On the other hand, studies have proven the effectiveness of laser therapy in repairing skin and mucous wounds that are difficult to heal17,18 and in reducing the pain caused by NT of women who breastfeed $5-7$ and both reported advantages of LLL therapy, with topical application, especially regarding its role in speeding up the repair process and relieving pain. However, to date, there are no 
Representativeness of cost on laser equipment, materials and qualified professional in each Lasertherapy session. Londrina, PR, Brazil, 2017 and 2018.
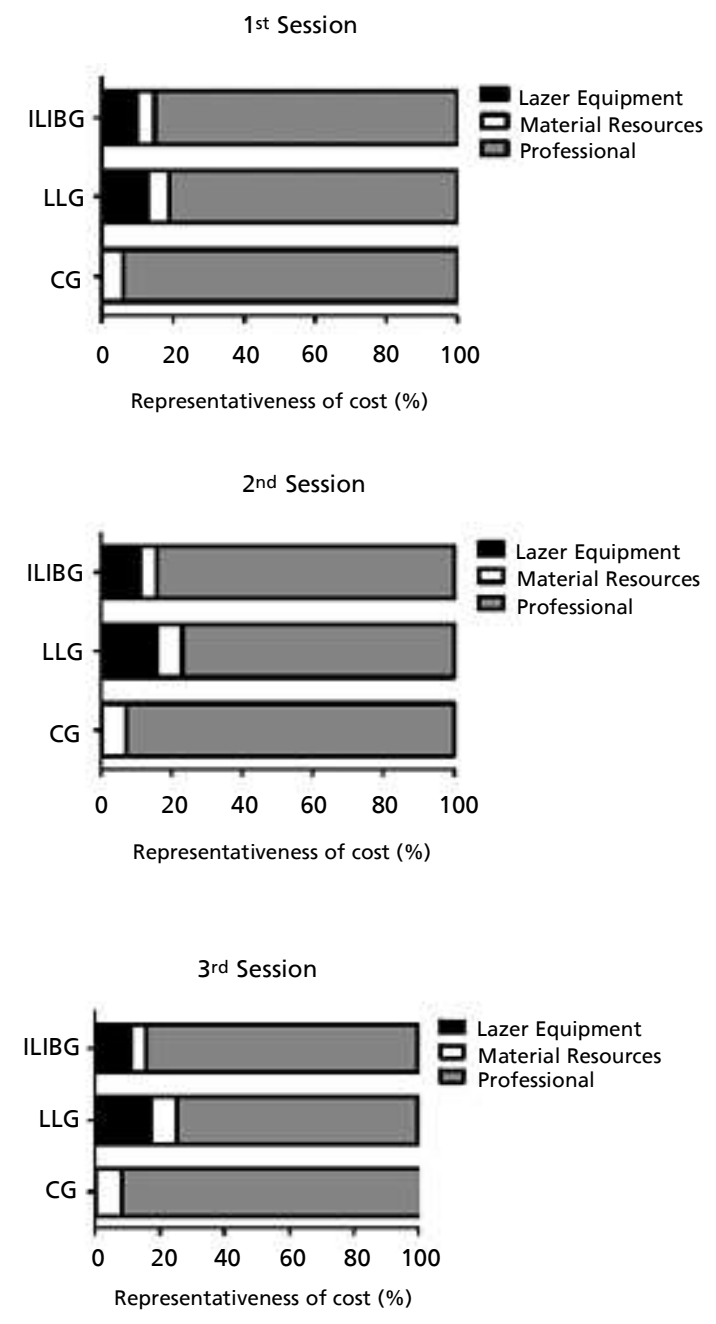

$\mathrm{ILIBG}=$ Irradiation Laser Intravascular of Blood Group; $\mathrm{LLG}=$ Local Laser Group; $\mathrm{CG}=$ Control Group 
Figure 3

Correlation between the duration of LL and ILIB Lasertherapy sessions and cost. Londrina, PR, Brazil, 2017 and 2018.
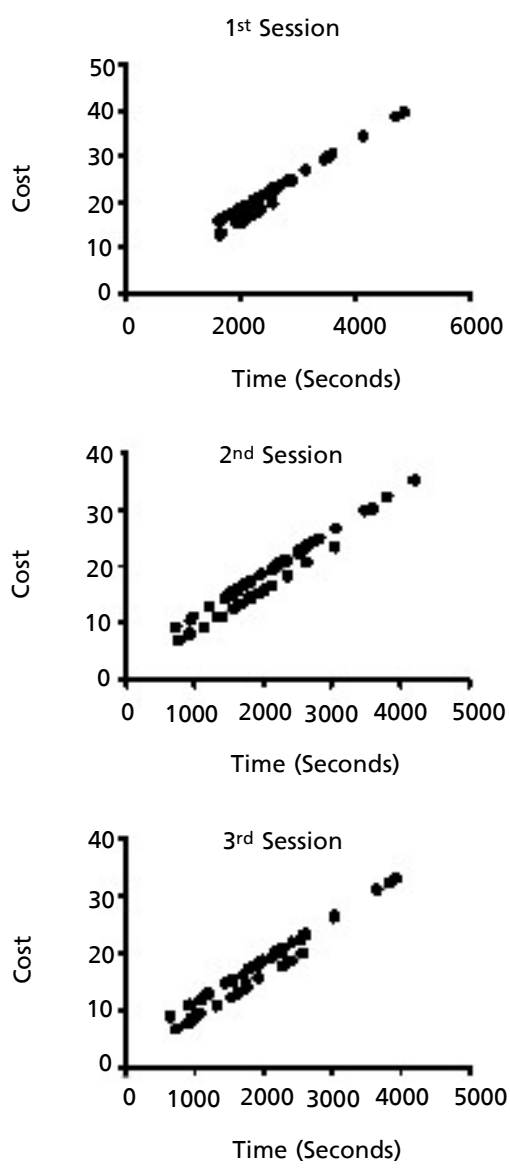

Table 1

Median (minimum - maximum) for the final $\Delta$ values and the total duration of three sessions of the CG, LLG and ILIBG. Londrina, PR, Brazil, 2017 and 2018.

\begin{tabular}{lll}
\hline Group & $\Delta$ final $(\mathbf{m m})$ & Total duration (seg.) \\
\hline CG & $-4(-133-100) *$ & $5035(3774-7615)^{*}$ \\
LLG & $-10(-282-50)$ & $5626(3251-8357) *$ \\
ILIBG & $-21(-204-30)$ & $7601(6444-12275)$
\end{tabular}

$\Delta$ Final delta = lesion area after the 3rd application - initial lesion area; total duration = session duration $1+$ session duration $2+$ session duration 3 .

* $p<0.05$ vs. ILIBG.

$\mathrm{CG}=$ Control Group; LLG= Local Laser Group; ILIBG= Irradiation Laser Intravascular of Blood Group. 
results from clinical trials using ILIB to compare results.

It should be noted that in this study it was possible to observe a significant improvement in wound healing in the two intervention groups (LLG and ILIBG), however the patients who received ILIB showed greater tissue recovery, accelerating the healing process, which increases the chances of keeping exclusive breastfeeding.

In this way, this study produced new scientific evidence that allows us to state statistically that ILIBG was more effective and that, although it has a higher cost, it has a positive cost-benefit ratio.

Regarding the healing of the lesion and the duration of therapy, it was evident that the longer the session, the smaller the final area of the lesion. Because of this, the total time was analyzed, and a significant distinction was found between the groups, CG and LLG have a cumulative duration of the three sessions significantly shorter when compared to ILIBG. However, when analyzing the improvement of the lesion, only ILIBG showed a greater reduction when compared to $\mathrm{CG}$.

A recent study has explained how laser irradiation can induce a photo biomodulation (PBM) effect on the cells and tissues, contributing to a targeted modulation of cellular behaviors, improving tissue repair processes, inducing cell proliferation, and increasing trunk cell differentiation. Laser therapy is a non-invasive method that contributes to pain relief and reduces inflammation, besides the improved healing and tissue repair processes. 19

A possible limitation of this study would be the non-stratification on different types of NT, since the area of the lesion was considered, which could interfere in the variation of the total cost. It is suggested in new studies to categorize this clinical variable when associated with costs. As a result, absolute values were not compared, Delta - $\Delta$, was performed to check the magnitude of the benefit in LLL, without losses.

It is a fact that breast milk is a differentiated food, adapted to the child's needs, providing nutrients that are necessary for their full growth and development, however in low-income and middle income countries, only $37 \%$ of the children under 6 months are exclusively breastfed. 1

An important study brings remarkable data. According to the authors, if women could exclusively breastfeed their children for the first six months of life, we would save 341.3 billion dollars worldwide annually in health costs. 20 However, these costs can be minimized by investing in public health policies that support, protect, promote, and extend breastfeeding.

When it comes to measuring the cost of a new technology that has not yet been incorporated in care protocols, it is important to consider the unquantifiable costs obtained from long-lasting breastfeeding. This is reflected in the biological benefits of breast milk, in the mother-child bond, in practicality and the lowest cost for families 18 and countless other aspects of the social cost of successful breastfeeding. In this perspective, economic aspects are important instruments to guide political decisions. Therefore, maternal and child health, too, must be considered an economic asset and be appreciated by society and health managers, who assign financial resources, given that the costs of this procedure were measured, this knowledge can be included in management decisions on alternatives for the NT treatment, which is the advance of knowledge in this study.

It was concluded that ILIB micro absorption cost was higher than the other alternatives treatment in all sessions. The most prominent variable in the composition of the cost was the nursing professional's assistance time. ILIB had a greater effect on NT healing when compared to CG and, even though it is more expensive, a positive cost-benefit ratio is suggested in healthcare practice, which gives this alternative treatment a greater saving.

An important contribution of the present study was to measure and make known the costs, being able to guide health professionals in the choice of the best therapeutic method, including cost information in the decision-making process.

There was an advance in knowledge, since ILIB transcutaneous laser therapy proved to be an effective and efficient alternative, being a low-cost alternative, which can be included into global protocols.

\section{Authors' contributions}

Nogueira DNG e Curan FMS performed conception and design of the research, data collection, analysis and interpretation, statistical analysis, writing and critical review of the manuscript. Cardelli AAM contributed on conception and design of the research, writing and critical review of the manuscript. Ferrari RAP contributed on conception and design of the research, Obtaining financing, writing and critical review of the manuscript. Tokushima $T$ contributed on data collection, analysis and interpretation, writing and critical review of the manuscript. Adraus RAC contributed conception and design of the research, writing and critical review of the manuscript. All authors approved the final version of the article. 


\section{References}

1. Victora CG, Bahl R, Barros AJ, França GV, Horton S, Krasevec J, Simon M, Jeeva S, Neff W, Nigel R, Katrina A, Shyamali D, Caroline L, Karen P, Nita B, Ranadip C, Bireshwar S, Sunita G, Elsa G, Linda R. Breastfeeding in the 21st century: epidemiology, mechanisms, and lifelong effect. Lancet. 2016; 387(10017): 475-90.

2. Cervellini MP, Antar GM, Pereira CK, Vilhena AACF. Lesões mamilares decorrentes da amamentação: um novo olhar para um problema conhecido. Rev Esc Enferm USP. 2014; 48 (2): 346-56.

3. Neves BR, Silva TS, Gomes DR, Mattos MP, Mendes ACCS, Gomes DR. Intercorrências mamárias relacionadas com à amamentação: uma revisão sistemática. Hígia. 2016; 1 (2): 58-73

4. Cotler HB, Chow RT, Hamblin MR, Carroll J. The use of Low Level Laser Therapy (LLLT) for musculoskeletal pain. MOJ Orthop Rheumatol. 2015; 2 (5): 00068.

5. Coca KP, Marcacine KO, Gamba MA, Correa L, Aranha AC, Abrão AC. Efficacy of low-level laser therapy in relieving nipple pain in breastfeeding women: a tripleblind, randomized, controlled trial. Pain Manag Nurs. 2016; 17 (4): 281-9.

6. Buck ML, Eckereder G, Amir LH. Low level laser therapy for breastfeeding problems. Breastfeed Rev. 2016; 24 (2): 27-31.

7. Pietchining B, Pane M, Kafer A, Bauer Wais E, Lischka A. Use of soft laser in the therapy of sore nipples in breastfeeding woman. Adv Exp Med Biol. 2000; 478: 437-8.

8. Meneguzzo DT, Ferreira LS, Carvalho EM, Nakashima CF. Intravascular laser irradiation of blood. In: Hamblin MR, Sousa, MVP, Agrawal T. Handbook of Low Lavel Laser Therapy. Singapore: Panstanford; 2017. p. 933-46.

9. COFEN (Conselho Federal de Enfermagem). Parecer n 13/2018/COFEN/CTLN COFEN. Dispõe sobre questionamento de profissional acerca do uso de laserterapia de baixa intensidade em lesões mamilares. O Parecer conclui que a utilização de meios fototerápicos é atividade compartilhada na saúde sendo inclusive utilizada pelo enfermeiro em curativos. Brasília; 2018. [acesso 12 ago 2020]. Disponível em: http://www.cofen.gov.br/parecer-n-13-2018-cofenctln_65231.html.

10. Brasil. Ministério da Saúde. Departamento de Atenção Básica, Secretaria de Atenção à Saúde. Política Nacional de Práticas Integrativas e Complementares no SUS - PNPICSUS. Brasília, DF; 2013

Received on April 16, 2020

Final version presented on October 13, 2020

Approved on December 28, 2020
11. Bittar OJNV. Saúde e administração. Bol Epidemiol Paul. 2015; 12 (139): 11-2.

12. Brasil. Ministério da Saúde. Secretaria de Atenção à Saúde. Departamento de Atenção Básica. Saúde da criança: nutrição infantil, aleitamento materno e alimentação complementar. Cadernos de Atenção Básica, 23. 2 ed. Brasília, DF; 2015.

13. Espírito Santo H, Daniel F. Calcular e apresentar tamanhos do efeito em trabalhos científicos (1): As limitações do $\mathrm{p}<$ 0,05 na análise de diferenças de médias de dois grupos. Rev Port Invest Comport Soc (RPICS). 2015; 1(1): 3-16.

14. Beulke R, Bertó DJ. Gestão de custos e resultados na saúde. 3 ed. São Paulo: Saraiva; 2013.

15. Ching HY. Manual de custos de instituições de saúde: sistemas tradicionais de custos e sistema de custeio baseado em atividades (ABC). São Paulo: Atlas; 2010

16. Dennis CL, Jackson K, Watson J. Interventions for treating painful nipples among breastfeeding women. Cochrane Database Syst Rev. 2014; (12): CD007366.

17. Rocha GP, Oliveira MCF, Ávila LBB, LG, Cotta RMM, Araújo RMA. Condicionantes da amamentação exclusiva na perspectiva materna. Cad Saúde Pública. 2017; 34 (6): e00045217.

18. Albrektson M, Hedstrom L, Bergh H. Recurrent aphthous stomatitis and pain management with low-level laser therapy: a randomized controlled trial. Oral Surg Oral Med Oral Pathol Oral Radiol. 2014; 117 (5): 590-4.

19. Dompe C, Moncrieff L, Matys J, Grzech-lésniak K, Kocherova L, Bryja A, Bruska M, Dominiak M, Mozdziak P, Skiba THI, Shibli JA, Volponi AA, Kempsty B, Dyszkiewicz-Konwińska M. Photobiomodulation-underlying mechanism and clinical applications. J Clin Med. 2020; 9(6): 1724 .

20. Walters D, Phan LTH, Mathisen R. The cost of not breastfeeding: global results from a new tool. Health Policy Plan. 2019; 34 (6): 407-17 